\title{
Biologicals in rheumatology: Austrian experiences from a rheumatic outpatient clinic
}

\author{
C. Duftner $\cdot$ C. Dejaco $\cdot$ H. Larcher $\cdot$ \\ M. Schirmer $\cdot$ M. Herold
}

Published online: 25 July 2008

(C) Springer-Verlag 2008

\section{Erratum to: Rheumatol Int}

\section{DOI 10.1007/s00296-008-0621-9}

Due to an unfortunate oversight Fig. 2 was rendered incorrectly. The correct Fig. 2 is given here:

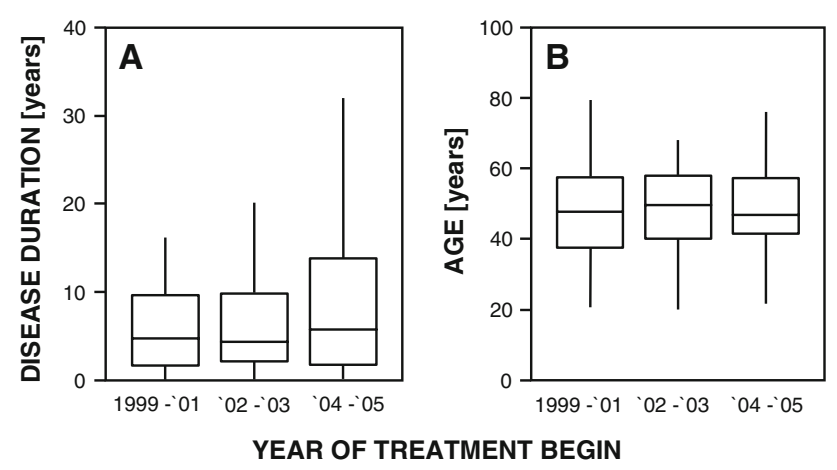

Fig. 2 Disease duration (a) and age at onset of first biological therapy (b) remained constant over the observation period. Whiskers box plots show $50 \%$ of cases within the boxes and all data excluding mavericks between the end-points of the whiskers (lines). Differences were not significant according to the Kruskal-Wallis test

The online version of the original article can be found under doi:10.1007/s00296-008-0621-9.

C. Duftner · C. Dejaco $\cdot$ H. Larcher $\cdot$ M. Schirmer $\cdot$ M. Herold Clinical Department of Internal Medicine,

Division of General Internal Medicine,

Innsbruck Medical University, Innsbruck, Austria

C. Duftner $(\varangle) \cdot$ C. Dejaco $\cdot$ M. Schirmer

Department of Internal Medicine,

General Hospital of the Elisabethinen,

Voelkermarkterstrasse 15-19, 9020 Klagenfurt, Austria

e-mail: christina.duftner@ekh.at 